\title{
New technologies and metabolic control in type 1 diabetes mellitus
}

\section{ABSTRACT}

The introduction of more rigorous criteria of metabolic control, rapid- and long-acting insulin analogues and the advances in diabetes technology (improved insulin delivery systems and blood glucose monitoring) have not been translated into better glycaemic control in patients with type 1 diabetes, which is quite similar to that observed 20-30 years ago in the Diabetes Control and Complications Trial (DCCT). Continuous subcutaneous insulin infusion (CSII) provided by personal insulin pumps may improve glycaemic control; however, observed results are not so good as it has been expected and are only slightly better or similar to these obtained with multiple daily insulin injections (MDII). Real-time continuous glucose monitoring (CGM) seems to be very useful to achieve target glycaemic control and to avoid hypoglycaemia in both CSII and MDII patients. While using CGM, levels of $\mathrm{HbA}_{1 \mathrm{c}}$ are lower, time spent in hypoglycaemia is shorter and frequency of hypoglycaemia episodes is reduced. To receive optimum benefit, excellent compliance and frequent readings of measurements are required. The most common real-time sensors used in Poland are: Medtronic Enlite, Dexcom G4 Platinum and Abbott FreeStyle Libre. Unfortunately, for majority of patients with type 1 diabetes CGM devices have no reimbursement. (Clin Diabetol 2017; 6, 3: 111-114)

Key words: type 1 diabetes, metabolic control, continuous glucose monitoring, advanced technologies

Address for correspondence:

lek. Mateusz Klamann

Klinika Diabetologii i Chorób Wewnętrznych

Pomorski Uniwersytet Medyczny

ul. Siedlecka 2, 72-010 Police

Phone: 914253855

e-mail: matklam@gmail.com

Translation: lek. Małgorzata Kamińska

Clinical Diabetology 2017, 6, 3, 111-114

DOI: $10.5603 /$ DK.2017.0018

Received: 11.08.2017

Accepted: 16.08 .2017

\section{Metabolic control in type 1 diabetes remains unsatisfactory}

According to current guidelines, recommended values of $\mathrm{HbA}_{1 \mathrm{c}}$ in young patients with type 1 diabetes are $\leq 6.5 \%$ or at least $\leq 7 \%$, while avoiding hypoglycaemia [1, 2]. Despite more rigorous criteria of metabolic control, the introduction of rapid- and long-acting insulin analogues and significant technological advances in insulin administration and glycaemic monitoring, metabolic control in type 1 diabetes patients remains unsatisfactory. In the US study involving more than 16,000 patients with type 1 diabetes treated in specialist centres, mean $\mathrm{HbA}_{1 \mathrm{c}}$ value was $8.4 \%$, although more than $60 \%$ of these patients were treated with personal insulin pumps [3]. Mean $\mathrm{HbA}_{1 \mathrm{c}}$ values were: in children $8.2 \%$ (younger children) to $8.5 \%$ (older children), in teenagers (13 to 17 years) $-9.0 \%$, in young adults (18 to 25 years) $-8.7 \%$ and in patients older than 25 years $-7.6 \%$. A maximum value of $9.2 \%$ was reported in 19-year-olds. Overall, target $\mathrm{HbA}_{1 \mathrm{c}}$ values were only observed in $23 \%$ of patients - in $22 \%$ of children, $17 \%$ of teenagers, $14 \%$ of young adults and $30 \%$ of those older than 25 years of age. In almost all age groups, diabetes control was worse than a few years ago. Unsatisfactory metabolic control was also observed in more than 27,000 young patients with type 1 diabetes assessed in Germany and Austria [4].

The results of these studies indicate that the metabolic control of type 1 diabetes has not changed significantly since the Diabetes Control and Complications Trial (DCCT), in the 1990s. It is worth recalling that in the DCCT mean $\mathrm{HbA}_{1 \mathrm{c}}$ value in the intensive group was $7.2 \%$, while in the conventionally treated group - $9.1 \%$ [5]. In the Epidemiology of Diabetes Interventions and Complications (EDIC) study, a continuation of the DCCT, despite intensification of treatment in all study participants, $\mathrm{HbA}_{1 \mathrm{c}}$ values were almost identical in both groups (approximately 8.0\%) [6]. 


\section{Effects of treatment with personal insulin pumps}

It is believed that the use of personal insulin pumps (PIPs) is superior to multiple daily insulin injection (MDII) regimen, but the effects are not as good as one would expect. In a follow-up study conducted in the USA, mean $\mathrm{HbA}_{1 \mathrm{c}}$ values in PIP and MDIl groups were as follows: in children under 13 years $-8.3 \%$ and $8.7 \%$, respectively; in 13-25-year-olds - $8.7 \%$ and $9.3 \%$; and in patients older than 25 years $-7.7 \%$ and $7.8 \%$. The analysis of randomized clinical trials in type 1 diabetes patients performed by Golden et al. showed that PIP and MDII were similarly effective in reducing $\mathrm{HbA}_{1 \mathrm{c}}$ and lowering the risk of severe hypoglycaemia in children and adolescents, while in adults there was a difference in $\mathrm{HbA}_{1 \mathrm{c}}$ values between patients treated with PIP and MDIl amounting to $0.3 \%$, in favour of PIP [8]. It should be stressed that the difference observed in adults in this meta-analysis was caused by the spectacular results of one study [9]. After excluding that study from the meta-analysis, PIP and MDII showed similar efficacy also in adults [8]. The very low advantage of PIP over MDII has also been confirmed by Misso et al. who analysed the results of 23 randomized clinical trials involving almost one thousand patients and confirmed a small difference in $\mathrm{HbA}_{1 \mathrm{c}}$ of approximately $0.3 \%$ in favour of pump therapy [10]. In this analysis, the incidence of mild hypoglycaemia was similar for PIP and MDII, while severe hypoglycaemia was observed less frequently in those using PIP. Personal insulin pump therapy was also associated with better quality of life of patients.

Recent clinical trials confirm previous observations $[11,12]$. The results of a randomized RESPOSE trial indicate that the introduction of PIP therapy in patients with type 1 diabetes is associated with effects similar to those of intensive insulin therapy with MDII [11]. After providing all the patients with the same intensive insulin therapy training, including insulin dose adjustment for food intake, current glycaemia and exercise, there were no significant differences in $\mathrm{HbA}_{1 c}$ values between PIP and MDII groups. The proportion of patients who achieved $\mathrm{HbA}_{1 \mathrm{c}} \leq 7.5 \%$ was similar in both groups and surprisingly low - after 6 months it was about $21 \%$, after 1 year $-23 \%$, and after 2 years -23 to $25 \%$. Both groups showed a significant and very similar reduction in the frequency of severe hypoglycaemia. The patients using PIP reported better quality of life and greater satisfaction with treatment. Another clinical trial - the COMISAIR Study - also showed slight differences in $\mathrm{HbA}_{1 \mathrm{c}}$ between patients with type 1 diabetes treated with PIP vs. MDII, with glucose self-monitoring conducted in both groups [12]. $\mathrm{HbA}_{1 \mathrm{c}}$ values in patients treated with PIP were lower in the consecutive one-year periods by $0.1-0.2 \%$ compared to those treated with the MDII, although this parameter has improved in both groups. The incidence of severe hypoglycaemia was similar in both groups.

\section{Effects of continuous glucose monitoring Impact on glycaemia}

It seems that the method that allows for a definite improvement in $\mathrm{HbA}_{1 \mathrm{c}}$ values in both PIP- and MDII-treated patients is continuous glucose monitoring (CGM). A large American observational study indicates that the use of CGM in patients with type 1 diabetes treated with PIP results in a reduction in $\mathrm{HbA}_{1 \mathrm{c}}$ level by $0.6 \%$ in children, $0.6 \%$ in adolescents and young adults and about $0.4 \%$ in patients older than 25 years. The use of CGM also has a significant effect on $\mathrm{HbA}_{1 \mathrm{c}}$ values in patients on MDII therapy. In children $\mathrm{HbA}_{1 \mathrm{c}}$ levels were reduced by $0.8 \%$, in adolescents and young adults by $1.1 \%$ and in patients over 25 years of age by $0.5 \%$ [7]. In all age groups, the patients using CGM had similar $\mathrm{HbA}_{1 \mathrm{c}}$ values regardless of whether they were on PIP or MDII. Data from a systematic review and meta-analysis of 14 studies involving more than 1.2 thousand patients with type 1 diabetes showed slightly lower effectiveness of CGM in improving glycaemic control [13]. The reduction of $\mathrm{HbA}_{1 \mathrm{c}}$ in subjects using CGM compared to standard self-monitoring group was only about $0.25 \%$ in children and adolescents and about $0.3 \%$ in adults. At the same time, a higher proportion of patients achieving $\mathrm{HbA}_{1 \mathrm{c}}$ targets and fewer hypoglycaemic episodes were observed in the CGM group [13].

However, the latest publications indicate that CGM is much more effective. A Czech study showed that the use of the CGM system significantly reduces $\mathrm{HbA1c}$ and lowers the risk of hypoglycaemia in both PIP- and MDIl-treated patients [12]. Over the 12 months of observation, $\mathrm{HbA}_{1 \mathrm{c}}$ values in the PIP-treated patients using CGM decreased by about $1.1 \%$, while in the MDII-treated patients using CGM, the $\mathrm{HbA}_{1 \mathrm{c}}$ reduction was approximately $1.3 \%$. In both groups, the difference in $\mathrm{HbA}_{1 \mathrm{c}}$ between $\mathrm{CGM}$ and standard self-monitoring (with both PIP and MDII) was approximately $0.8 \%$ at the end of the study. The test results have been the basis for the statement that the MDII method combined with CGM may be an equivalent alternative to the PIP therapy with CGM. The data from the GOLD and DIAMOND trials confirm high effectiveness of CGM in patients treated with MDII $[14,15]$. In CGM patients, $\mathrm{HbA}_{1 \mathrm{c}}$ values were lower by 0.4 to $0.6 \%$ compared to those using standard self-monitoring.

The above-mentioned studies (GOLD and DIAMOND) as well as the IMPACT study have shown that good cooperation with patients and patients' compli- 
ance of at least $80 \%$ is a prerequisite for improvement in metabolic control [14-16].

According to other authors, combining PIP with CGM is particularly beneficial, because the $\mathrm{HbA}_{1 \mathrm{c}}$ values in patients using this type of therapy may be $0.6 \%$ lower than in those using CGM with MDII [17].

\section{Hypoglycaemia risk reduction}

An increased risk of hypoglycaemia is an important factor limiting the effectiveness of treatment in type 1 diabetes. Continuous glucose monitoring systems contribute to better glycaemic control by more efficiently adjusting insulin doses to glycaemic trends and reducing the incidence of hypoglycaemia, or at least not affecting its frequency [8, 13]. CGM also allows for shortening of the total time of hypoglycaemia. In a study conducted in children and adults with type 1 diabetes and $\mathrm{HbA}_{1 \mathrm{c}}<7.5 \%$, total daily time of hypoglycaemia in subjects with standard self-monitoring was $0.97 \pm 1.55$ hours, while in subjects using CGM it was $0.48 \pm 0.57$ hours. Continuous glucose monitoring was associated with reduced hypoglycaemia time and a decrease in $\mathrm{HbA}_{1 \mathrm{c}}$ levels [18]. A similar reduction in time spent in hypoglycaemia (from $11.4 \%$ to $6.8 \%$ ) was found in the IN CONTROL study, which also showed a 3-fold reduction in the incidence of severe hypoglycaemia [19]. In a Juvenile Diabetes Research Foundation (JDRF) study performed in patients with well-controlled metabolic syndrome $\left(\mathrm{HbA}_{1 \mathrm{c}}<7 \%\right)$, after 6 months of CGM, time spent with glycaemia $<70 \mathrm{mg} / \mathrm{dL}$ was reduced by more than $40 \%$, although no difference was observed in the frequency of hypoglycaemia and severe hypoglycaemia [20].

\section{Continuous glucose monitoring systems}

Devices for continuous glucose monitoring have been used in clinical practice for several years. Practical application in self-monitoring is limited to real-time glucose concentration recorders. The order of appearance of these devices is as follows: GlucoWatch G2, Medtronic RT-Guardian, Abbott FreeStyle Navigator CGM, Medtronic RT-CGM, Dexcom SEVEN Plus, Medtronic Enlite, Dexcom G4 Platinum, and Abbott FreeStyle Libre [21]. Almost all, except for the latter, require 2 to 4 calibrations per day by measuring capillary blood glucose with classic glucose meter. Alarms can be set for certain glycaemic values. The exception is the latest FreeStyle Libre ${ }^{\mathrm{TM}}$ device, which uses a new "flash" technology and is calibrated by the manufacturer. Hence this device does not need to be calibrated by the patient using capillary blood glucose. The device shows current glucose concentrations and trends, but unlike the others, it has no alarm function. In Poland, the most common systems for continuous monitoring of blood glucose are: Medtronic Enlite, Dexcom G4 Platinum and Abbott FreeStyle Libre. These systems consist of a sensor, a transmitter and a monitor device. The CGM technology is based on a semi-invasive method of detecting of the current generated in the glucose oxidase-catalysed reaction by the sensor placed in the subcutaneous tissue. This enzyme is responsible for the oxidation of $\beta$-D-glucopyranose of the intracellular fluid to gluconic acid. Values recorded by the sensor are converted into glucose concentration in the recording device. The sensor can be placed precisely in subcutaneous tissue with a special inserting device (a serter) within the areas of the body where the thickness of the subcutaneous fat is sufficient. The location of the sensor is dependent on the clothes worn, convenience, individual preference or experience. It is recommended to avoid sites of recent insulin administration. Manufacturers of CGM recommend the abdominal area, upper buttocks, and arms as sensor locations; however, every sensor manufacturer has its own recommendations. The transmitter is connected to the sensor. Often, the sensor and the transmitter are an inseparable whole. The role of the transmitter is to transmit data to a monitoring device that can be an independent tool and can also be integrated into an insulin pump.

Increasingly frequent use of continuous glucose monitoring systems increases the involvement of patients in controlling their own disease, which contributes to $\mathrm{HbA}_{1 \mathrm{c}}$ reduction without increasing the risk of hypoglycaemia. Unfortunately, continuous glucose monitoring systems are not reimbursed for patients over 18 years of age by the National Health Fund.

\section{REFERENCES}

1. Polskie Towarzystwo Diabetologiczne (PTD): Zalecenia kliniczne dotyczące postępowania u chorych na cukrzycę 2017. Stanowisko Polskiego Towarzystwa Diabetologiczne. Diabetol Klin. 2017; 3(Suppl. A): A1-A81.

2. American Diabetes Association. Standards of Medical Care in Diabetes - 2017. Diabetes Care 2017; 40(Suppl. 1): S1-S135. Diabetes Care. 2017; 40(1): S1-S132.

3. Miller KM, Foster NC, Beck RW, et al. Current State of Type 1 Diabetes Treatment in the U.S.: Updated Data From the T1D Exchange Clinic Registry. Diabetes Care. 2015; 38(6): 971-978, doi: 10.2337/dc15-0078, indexed in Pubmed: 25998289.

4. Gerstl EM, Rabl W, Rosenbauer J, et al. Metabolic control as reflected by $\mathrm{HbA} 1 \mathrm{c}$ in children, adolescents and young adults with type-1 diabetes mellitus: combined longitudinal analysis including 27,035 patients from 207 centers in Germany and Austria during the last decade. Eur J Pediatr. 2008; 167(4): 447-453, doi: 10.1007/s00431-007-0586-9, indexed in Pubmed: 17924142.

5. The Diabetes Control and Complications Trial Research Group: The Effect of Intensive Treatment of Diabetes on the Development and Progression of Long-Term Complications in Insulin-Dependent Diabetes Mellitus. N. Eng. J. Med. 1993; 329(14): 977-986, doi: 10.1056/nejm199309303291401, indexed in Pubmed: 8366922. 
6. Nathan DM, Cleary PA, Backlund JY JY, et al. The Diabetes Control and Complications Trial/Epidemiology of Diabetes Interventions and Complications (DCCT/EDIC) Study Research Group: Intensive diabetes treatment and cardiovascular disease in patients with type 1 diabetes. Engl. J. Med. 2005; 353: 2643-2653.

7. Foster NC, Miller KM, Tamborlane WV, et al. Continuous Glucose Monitoring in Patients With Type 1 Diabetes Using Insulin Injections. Diabetes Care. 2016; 39(6): e81-e82, doi: 10.2337/dc160207, indexed in Pubmed: 27208319.

8. Golden SH, Brown T, Yeh HC, et al. Methods for insulin delivery and glucose monitoring: Comparative effectiveness. Review No. 57. (prepared by Johns Hopkins University Evidence-based Practise Center under contract No. 290-2007-10061-I). AHRQ Publication No. 12-EHC036-EF. Rockville. Agency for Healthcare Research and Quality. 2012.

9. DeVries JH, Snoek FJ, Kostense PJ, et al. A Randomized Trial of Continuous Subcutaneous Insulin Infusion and Intensive Injection Therapy in Type 1 Diabetes for Patients With Long-Standing Poor Glycemic Control. Diabetes Care. 2002; 25(11): 2074-2080, doi: 10.2337/diacare.25.11.2074, indexed in Pubmed: 12401759.

10. Misso M, Egberts K, Page M, et al. Cochrane review: Continuous subcutaneous insulin infusion (CSII) versus multiple insulin injections for type 1 diabetes mellitus. Evidence-Based Child Health: A Cochrane Review Journal. 2010; 5(4): 1726-1867, doi: 10.1002/ebch.623.

11. REPOSE Study Group. Relative effectiveness of insulin pump treatment over multiple daily injections and structured education during flexible intensive insulin treatment for type 1 diabetes: cluster randomised trial (REPOSE). BMJ. 2017; 356: j1285, doi: 10.1136/bmj.j1285, indexed in Pubmed: 28360027.

12. Soupal J, Petruzelkova L, Flekac M, et al. Comparison of Different Treatment Modalities for Type 1 Diabetes, Including Sensor-Augmented Insulin Regimens, in 52 Weeks of Follow-Up: A COMISAIR Study. Diabetes Technol Ther. 2016; 18(9): 532-538, doi: 10.1089/ /dia.2016.0171, indexed in Pubmed: 27482825.

13. Wojciechowski P, Ryś P, Lipowska A, et al. Efficacy and safety comparison of continuous glucose monitoring and self-monitoring of blood glucose in type 1 diabetes: systematic review and metaanalysis. Pol Arch Med Wewn. 2011; 121(10): 333-343, indexed in Pubmed: 22045094.
14. Lind M, Polonsky W, Hirsch IB, et al. Continuous Glucose Monitoring vs Conventional Therapy for Glycemic Control in Adults With Type 1 Diabetes Treated With Multiple Daily Insulin Injections: The GOLD Randomized Clinical Trial. JAMA. 2017; 317(4): 379-387, doi: 10.1001/jama.2016.19976, indexed in Pubmed: 28118454.

15. Beck RW, Riddlesworth T, Ruedy K, et al. DIAMOND Study Group. Effect of Continuous Glucose Monitoring on Glycemic Control in Adults With Type 1 Diabetes Using Insulin Injections: The DIAMOND Randomized Clinical Trial. JAMA. 2017; 317(4): 371-378, doi: 10.1001/jama.2016.19975, indexed in Pubmed: 28118453.

16. Bolinder J, Weltgasser R, Antuna R, et al. Novel glucose-sensing technology and hypoglycaemia in type 1 diabetes: a multicentre, non-masked, randomised controlled trial. Lancet. 2016; 388(10057): 2254-2263, doi: 10.1016/s0140-6736(16)31535-5.

17. Ruiz-de-Adana M, Dominguez-Lopez ME, Gonzalez-Molero I, et al. Comparison between a multiple daily insulin injection regimen (basal once-daily glargine plus mealtime lispro) and continuous subcutaneous insulin infusion (lispro) using continuous glucose monitoring in metabolically optimized type 1 diabetes patients: A randomized open-labelled parallel study. Med. Clin. 2016; 146(6): 239-246, doi: 10.1016/j.medcli.2015.09.020, indexed in Pubmed: 26656958.

18. Battelino T, Phillip M, Bratina N, et al. Effect of continuous glucose monitoring on hypoglycemia in type 1 diabetes. Diabetes Care. 2011 ; 34(4): 795-800, doi: 10.2337/dc10-1989, indexed in Pubmed: 21335621.

19. van Beers C, DeVries J, Kleijer S, et al. Continuous glucose monitoring for patients with type 1 diabetes and impaired awareness of hypoglycaemia (IN CONTROL): a randomised, open-label, crossover trial. Lancet Diabetes Endocrinol. 2016; 4(11): 893-902, doi: 10.1016/s2213-8587(16)30193-0, indexed in Pubmed: 27641781.

20. Juvenile Diabetes Research Foundation Continuous Glucose Monitoring Study Group J J, Beck RW, Hirsch IB. The Effect of Continuous Glucose Monitoring in Well-Controlled Type 1 Diabetes. Diabetes Care. 2009; 32(8): 1378-1383, doi: 10.2337/dc09-0108, indexed in Pubmed: 19429875.

21. Facchinetti A. Continuous Glucose Monitoring Sensors: Past, Present and Future Algorithmic Challenges. Sensors (Basel). 2016; 16(12): 2093, doi: 10.3390/s16122093, indexed in Pubmed: 27941663. 